Int. J. Electrochem. Sci., 14 (2019) $3301-3314$

\title{
Graphene/Carbon Nanotubes Composite as a Polysulfide Trap for Lithium-Sulfur Batteries
}

\author{
Feng Gao ${ }^{1,2}$, Xinxiu Yan ${ }^{1,2}$, Zhikai Wei ${ }^{1}$, Meizhen Qu ${ }^{1}$, Weifeng Fan ${ }^{1, *}$ \\ ${ }^{1}$ Chengdu Institute of Organic Chemistry, Chinese Academy of Sciences, Chengdu 610041, P.R. \\ China. \\ ${ }^{2}$ University of Chinese Academy of Sciences, Beijing 100049, P.R. China. \\ *E-mail: $\underline{\text { fanwf@cioc.ac.cn }}$
}

doi: $10.20964 / 2019.04 .16$

Received: 12 December 2018 / Accepted: 17 January 2019 / Published: 10 March 2019

\begin{abstract}
Separator modified with graphene/carbon nanotube composite (G/CNT) is introduced into lithium-sulfur (Li-S) battery to trap and activate the soluble polysulfides. The Li-S battery based on a novel separator allows sulfur cathode to reach a high initial discharge capacity of $1200 \mathrm{mAh} . \mathrm{g}^{-1}$ at $0.2 \mathrm{C}$ and a reversible capacity of $815 \mathrm{mAh} . \mathrm{g}^{-1}$ after 100 cycles at $0.5 \mathrm{C}$, which led to an excellent rate capability (up to $2 \mathrm{C}$ rate) and a high Coulombic efficiency of $99 \%$. In this study, the role of separator modified with G/CNT in the electrochemistry of Li-S batteries was also systematically explored. The electrical conductivity and the special leaf stack structure of G/CNT layer have a synergistic effect in controlling the shuttle effect of polysulfides. Moreover, the G/CNT layer can compensate for the effects of deterioration of the morphology of sulfur cathode.
\end{abstract}

Keywords: Lithium-sulfur battery; Carbon nanotube; Graphene; Modified separator; Shuttle effect

\section{FULL TEXT}

(C) 2019 The Authors. Published by ESG (www.electrochemsci.org). This article is an open access article distributed under the terms and conditions of the Creative Commons Attribution license (http://creativecommons.org/licenses/by/4.0/). 